\title{
Systematic Features of High-Frequency Volatility in Australian Electricity Markets: Intraday Patterns, Information Arrival and Calendar Effects
}

\author{
Helen Higgs ${ }^{*}$ and Andrew C. Worthington ${ }^{* *}$
}

This paper investigates the intraday price volatility process in four Australian wholesale electricity markets; namely New South Wales, Queensland, South Australia and Victoria. The data set consists of half-hourly electricity prices and demand volumes over the period 1 January 2002 to 1 June 2003. A range of processes including GARCH, Risk Metrics, normal Asymmetric Power ARCH or APARCH, Student APARCH and skewed Student APARCH are used to model the timevarying variance in prices and the inclusion of news arrival as proxied by the contemporaneous volume of demand, time-of-day, day-of-week and month-of-year effects as exogenous explanatory variables. The skewed Student APARCH model, which takes account of right skewed and fat tailed characteristics, produces the best results in three of the markets with the Student APARCH model performing better in the fourth. The results indicate significant innovation spillovers (ARCH effects) and volatility spillovers (GARCH effects) in the conditional standard deviation equation, even with market and calendar effects included. Intraday prices also exhibit significant asymmetric responses of volatility to the flow of information.

\section{INTRODUCTION}

Australia has been at the forefront of global efforts to introduce competition into the electricity industry. Where electricity was once supplied by state government-owned entities, the market is now characterized by separation of the generation, transmission and distribution functions across commercialized and privatized companies. The ongoing process of restructuring and deregulation has already gone far in promoting a competitive national electricity market in Australia. And on the whole, the electricity spot markets integral to this restructuring process have achieved the key objective of lowering the wholesale price of electricity. But while lower prices for electricity are an encouraging sign, they have been accompanied by higher price volatility.

The prospect that this increased volatility will persist and likely increase in the future is a matter of interest to market participants. When prices are volatile there can be uncertainty about generators' revenues and suppliers' costs. Measures of risk are equally important to those managing energy commodity portfolios. Similarly, for those valuing derivatives, forecasts of volatilities over

Corresponding author School of Economics and Finance, Queensland University of Technology, Brisbane, Queensland 4000, Australia E-mail: h.higgs@qut.edu.au

School of Accounting and Finance, University of Wollongong, Wollongong, New South Wales 2500, Australia. E-mail: andrew.worthington@uow.edu.au 
the life of an instrument are required, while extreme observations imply changes to option values. Value-at-risk calculations can also benefit from a more thorough knowledge of price variance. Lastly, higher price volatility is a concern for industry regulators and market management companies because of unease that it may be partly the outcome of regulatory failure associated with inadequacies in market design and the exercise of market power.

All the same, it is accepted that the inherent characteristics of these newly competitive electricity markets also have a role to play in the higher observed price volatility. Given the nonstorability of electricity, higher-than-expected demand, poorly developed transmission networks, changes in purchasing and contracting behavior, inappropriately designed market mechanisms, market power and information asymmetry, amongst others, can provide a load-matching problem so that electricity shows seasonal, week-day and even intraday patterns in price level and volatility. Any satisfactory explanation of price volatility in electricity markets must be able to accommodate these striking empirical regularities.

It is also necessary to take into account the pronounced volatility clustering observed in these markets. Autoregressive conditional heteroskedasticity (ARCH) models allow volatility shocks to cluster and persist over time and to revert to some more normal level and so may offer potentially interesting insights on the volatility observed in electricity markets. Unfortunately, few ARCH-type studies of electricity prices have been undertaken in Australia or elsewhere [for exceptions see Escribano, Pena, and Villaplana (2002), Solibakke (2002) and Worthington, Kay-Spratley, and Higgs (2003) for spot electricity and Walls (1999) for electricity futures], and as far as the authors are aware, none which attempt to capture the arrival of intraday information effects

Accordingly, the purpose of this paper is to investigate the intraday price volatility process in Australian electricity markets by employing five different ARCH processes: namely, GARCH (generalised ARCH), Risk Metrics (normal integrated GARCH), normal APARCH (asymmetric power ARCH), Student APARCH and skewed Student APARCH (following Ding, Granger, and Engle, 1993; and Giot and Laurent, 2003a, 2003b). By including systematic features - intraday, intraday and monthly patterns (calendar effects), intraday innovation and volatility spillovers (ARCH and GARCH effects) and market activity (demand and information asymmetry effects) such an approach provides a comprehensive characterization of the volatility process. It thereby provides both a starting point for understanding the intrinsic price volatility in electricity markets, distinguishing it from changes in volatility that are thought to arise, say, from regulatory design and the exercise of market power. The remainder of the paper is divided into four sections. The second section explains the data employed in the analysis and presents some brief descriptive statistics. The 
third section discusses the methodology employed. The results are dealt with in the fourth section. The paper ends with some brief concluding remarks in the final section.

\section{DATA AND DESCRIPTIVE STATISTICS}

In brief, the Australian National Electricity Market (NEM) encompasses the four state-based regional markets of New South Wales (NSW), Queensland (QLD), South Australia (SA) and Victoria (VIC) operating as an interconnected grid coordinated by the National Electricity Market Management Company (NEMMCO). For the most part these regional markets operate separately because while power can be transmitted between regions, it is very much constrained by the physical transfer capacity of the regional interconnections. In each market, generators are required to submit bidding schedules on a half-hourly day-before basis. Matching expected demand in the next five minutes against the bid stack for that half-hour period sets prices and the price offered by the last generator (plant are dispatched on a least-cost basis) to meet total demand sets the fiveminute price. The pool price is the time-weighted average of the six five-minute periods comprising each half-hour trading period. This is the price generators receive for the electricity they dispatch into the pool, and is the price customers pay to receive generation in that half hour period [for details see Dickson and Warr (2000), IEA (2001) and NEMMCO (2001, 2003)].

The data employed in the study consists of electricity prices and demand volumes for the halfhourly intervals from 1 January 2002 to 1 June 2003 for each of the four wholesale electricity markets. All data is obtained from NEMMCO on a half-hourly basis representing 48 trading intervals in each 24-hour period (NEMMCO, 2003). The prices are in Australian dollars per megawatt hour (MWh). By way of comparison, De Vany and Walls (1999a; 1999b), Robinson (2000), Wolak (2000), Lucia and Schwartz (2001), Escribano, Pena, and Villaplana (2002), Solibakke (2002) and Worthington, Kay-Spratley, and Higgs (2003) employ daily prices in their respective analyses of the western United States, United Kingdom, Scandinavian and Australian electricity markets. Importantly, the use of daily prices may lead to the loss of at least some 'news' impounded in the more frequent trading interval data. The natural log of the price for each halfhourly interval is used to produce a time series of price relatives, such that $p_{t}=\log \left(g_{t} / g_{t-1}\right) \times 100$ where $g_{t}$ and $g_{t-1}$ represent the half-hourly pool generation prices at time $t$ and $t$-1, respectively.

\section{$<$ TABLE 1 HERE $>$}

Table 1 presents the summary of descriptive statistics of the price relatives for the four electricity markets. Sample means, medians, maximums, minimums, standard deviations, skewness, kurtosis and the Jarque-Bera (JB) statistic are reported. As shown, while the price relatives in all 
four markets are very small, the maximum, minimum and standard deviation of price relatives indicate much variability. The highest average price relatives are in QLD and SA, while the greatest positive price relatives are in QLD and VIC with the largest negative price relatives in NSW and SA. The standard deviations of price relatives range from 22.4033 (NSW) to 29.4379 (QLD). For the four markets, the value of the coefficient of variation (not shown) (standard deviation divided by the mean price change) measures the degree of variation in price relatives to the mean price change. On this basis, VIC is the most variable while NSW is the least variable.

\section{$<$ FIGURE 1 HERE $>$}

The distributional properties of the price relative series appear non-normal. All of the markets are significantly positively skewed ranging from 0.2788 (SA) to 1.0585 (VIC) indicating the greater likelihood of large price increases than price falls. The kurtosis, or degree of excess, is also large, ranging from 76.4694 for SA to 84.3674 for NSW, thereby indicating leptokurtic or heavy-tailed distributions with many extreme observations. The calculated Jarque-Bera statistic and corresponding $p$-value in Table 1 is used to test the null hypotheses that the intraday distribution of price relatives is normally distributed. All $p$-values are smaller than the 0.01 level of significance indicating the null hypothesis is rejected. These intraday price relatives are then not well approximated by the normal distribution; such conditions implying it is necessary to fit ARCH-type volatility models. Visual inspection of the price relative series in Figure 1 is also suggestive of the volatility clustering expected in these markets.

\section{MODEL SPECIFICATION}

The distributional properties of Australian spot electricity prices indicate that generalized autoregressive conditional heteroskedasticity $(\mathrm{GARCH})$ models can be used to examine the dynamics of the electricity price volatility process. Autoregressive conditional heteroskedasticity (ARCH) models [as introduced by Engle (1982)], generalized ARCH (GARCH) models [as proposed by Bollerslev (1986)] and asymmetric power ARCH (APARCH) introduced by Ding, Granger, and Engle (1993) that take into account the time-varying variances of time series data have already been widely employed in financial markets. Suitable surveys of ARCH modeling in general and/or its widespread use may be found in Bera and Higgins (1993) and Bollerslev, Chou and Kroner (1992). Ding, Granger, and Engle (1993), Pagan (1996), Giot and Laurent (2003a, 2003b) and Laurent (2004) also discuss developments in this ever-expanding literature.

To start with, a basic requirement is to remove the predictable component of the electricity price relatives so as to produce price relative innovation, $e_{t}$, with a conditional mean of zero before 
a GARCH equation is specified for the variance. One common method to produce an uncorrelated process in the half-hourly price relatives is to assume that they follow an AR (1) process. The following conditional expected price relative equation accommodates each market's own price relative and its price relative lagged one period:

$$
p_{t}=\tau_{0}+\tau_{1} p_{t-1}+e_{t}
$$

where $p_{t}$ is the price relative for each electricity market in the current period and $p_{t-1}$ is the price relative lagged one period, $\tau_{0}$ represents the long-term drift coefficient and $\tau_{1}$ is the degree of mean spillover effect across time, or put differently, whether the lagged price relative can be used to predict the current price relative, and $e_{t}$ is the random error or innovation at time $t$.

The next requirement is to model the variance of the price relative innovation itself. A GARCH process of order 1 and 1 , denoted as GARCH $(1,1)$, with the random error term, $e_{t}$, is specified as:

$$
e_{t}=h_{t} \varepsilon_{t} \quad \varepsilon_{t} \sim \text { iid } N(0,1)
$$

and the conditional variance (volatility) of $e_{t}$ at time $t$ is represented as:

$$
h_{t}^{2}=\alpha_{0}+\alpha_{1} e_{t-1}^{2}+\beta_{1} h_{t-1}^{2}
$$

where $h_{t}$ is the conditional standard deviation of volatility of $e_{t}$ at time $t, \alpha_{0}$ is a constant, $\alpha_{1}$ and $\beta_{1}$ are coefficients that are associated with the past values of innovation spillover $e_{t-i}^{2}$ to the current volatility, and thereby represent news about the degree of innovation from previous periods (ARCH term) and previous period's forecast volatility spillover effects (GARCH term).

A concern with the volatility generation process as defined is that current volatility is only related to the past values of innovation and volatility spillovers from previous periods. For example, Lamoureux and Lastrapes (1990) Engle and Ng (1993), Foster (1995), Andersen (1996), Andersen and Bollerslev (1997, 1998), Wang and Yau (2000) and Rahman, Lee and Ang (2002), amongst others, argue that an appealing explanation for the presence of GARCH effects in financial markets is that the rate and timing of information arrival is the stochastic mixing variable that generates financial market returns. That is, market information, however defined, is strongly correlated with price volatility (Andersen and Bollerslev 1998). It is also likely that some important electricity market information is reflected in the time-of-day, day-of-week and month-of-year in much the same manner. In this paper, and with the high-frequency data used, it is hypothesized that at least some relevant information is included in the contemporaneous volume of demand, the direction of price relatives and the time-of-day, week and month. Solibakke (2002), for example, found that price volatility in the Nordic spot electricity market increased strongly on Mondays and Saturdays and was especially strong during May, June and July. Herbert (2002: 34) also presented evidence 
that "...there is seasonality in (electricity) price risk. Not surprisingly, price risk increases in the summer...power prices also increase in the winter". And Hadsell, Marathe and Shawky (2004) found that volatility behaviour differed by month across five US electricity markets.

The next methodological requirement is to then model volatility including such information effects. The conditional variance equation, rather than the conditional mean equation, should take account of the time-varying conditional heteroskedasticity caused by changes in the contemporaneous volume of demand and seasonal and random fluctuations since the variance measures the risk generated by new information. For example, Hadsell, Marathe and Shawky (2004) included monthly dummies in the conditional variance equation describing US electricity markets, while Rahman, Lee and Ang (2002) introduced contemporaneous and lagged volume of demand and bid-ask spread in the conditional variance equation describing US financial markets. Five different GARCH volatility processes, namely GARCH, Risk Metrics, normal APARCH, Student APARCH and skewed Student APARCH models are employed, all of which include information effects as defined, but vary according to the assumed distribution of the random error term and/or the conditional standard deviation equation.

To start with, and to take account of the incidence of the time varying conditional heteroskedasticity that could be due to an increase in market information in the form of the contemporaneous volume of demand and time-of-day, day-of-week and month-of-year effects following the simultaneous arrival of new information, the random error term, $e_{t}$ as previously defined in (2) and the GARCH conditional variance equation in (3) is reformulated as:

$$
h_{t}^{2}=\alpha_{0}+\alpha_{1} e_{t-1}^{2}+\beta_{1} h_{t-1}^{2}+\psi_{1} v_{t}+\sum_{i=2}^{48} \varphi_{i} d_{i}+\sum_{i=2}^{7} \eta_{i} w_{i}+\sum_{i=2}^{12} \varsigma_{i} m_{i}
$$

where $v_{t}$ represents the contemporaneous volume of demand, $d_{i}$ are dummy variables for the timeof-day having values of one for the second half hour $d_{2}$ (0:30-1:30 hours) and zero otherwise; $w_{i}$ are dummy variables for each day of the week having values of one for $w_{2}$ (Tuesday) and zero otherwise; $m_{i}$ are dummy variables for each month of the year having values of 1 for $m_{2}$ (February) and zero otherwise, and $\varphi_{i}, \eta_{i}$ and $\zeta_{i}$ are coefficients. The midnight half-hour, Monday and January are the reference categories in the calendar effects and all other variables are as previously defined.

Second, the Risk Metrics model is equivalent to a normal integrated GARCH (IGARCH) model where the autoregressive parameter of the conditional variance equation is preset to a specified value of $\lambda=0.94$ and the parameter of the squared random error or innovation term is $1-\lambda$. The Risk Metrics model has the random error term, $e_{t}$, as specified in (2) and the conditional variance equation in (4) is reformulated as: 


$$
h_{t}^{2}=\alpha_{0}+(1-\lambda) e_{t-1}^{2}+\lambda h_{t-1}^{2}+\psi_{1} v_{t}+\sum_{i=2}^{48} \varphi_{i} d_{i}+\sum_{i=2}^{7} \eta_{i} w_{i}+\sum_{i=2}^{12} \varsigma_{i} m_{i}
$$

This model is introduced to take account of the large positive and negative price relative spikes found in the Australian electricity market. Accordingly, the goodness-of-fit of the Risk Metrics model depends on its ability to predict these large positive and negative price relatives.

Third, the normal APARCH model (Ding, Granger, and Engle, 1993) is yet another extension of the GARCH model (Bollerslev 1986). In the normal APARCH the random error term, $e_{t}$, is specified as in (2) and the conditional standard deviation, $h_{\mathrm{t}}$, in (4) is respecified as:

$$
h_{t}^{\delta}=\alpha_{0}+\alpha_{1}\left(\left|e_{t-1}\right|-\gamma_{1} e_{t-1}\right)^{\delta}+\beta_{1} h_{t-1}^{\delta}+\psi_{1} v_{t}+\sum_{i=2}^{48} \varphi_{i} d_{i}+\sum_{i=2}^{7} \eta_{i} w_{i}+\sum_{i=2}^{12} \varsigma_{i} m_{i}
$$

where $\alpha_{0}>0, \alpha_{1}, \beta_{1}$ and $\delta \geq 0$ and $-1<\gamma_{1}<1$ are parameters to be estimated and all other variables are as previously defined. This model introduces a non-linear relationship between the conditional standard deviation and the lagged and lagged absolute random errors by imposing a Box-Cox transformation, $\delta(\delta>0)$. The asymmetric volatility response to negative and positive shocks such that volatility tends rise in response to 'bad news' and fall in response to 'good news' is reflected in a positive value of the parameter $\gamma_{1}$. This APARCH process encompasses Bollerslev's (1986) GARCH with $\delta=2$ and $\gamma_{1}=0$, the Taylor (1986)/Schwert (1990) model with $\delta=1$ and $\gamma_{1}=0$ and five other GARCH processes (Ding, Granger, and Engle, 1993).

Fourth, the Student APARCH model is an extension of the normal APARCH model (Ding, Granger, and Engle, 1993). The Student APARCH is introduced to take account of the fat-tailed characteristic of Australian electricity markets (Bauwens and Giot, 2001, Alexander, 2001 and Giot and Laurent, 2003a and 2003b). The Student APARCH where the random error term is defined as $e_{t}=h_{t} \varepsilon_{t}$ and $\varepsilon_{t} \sim$ iid $t(0,1, v)$ and $v$ is the degrees of freedom and the conditional standard deviation, $h_{t}$, is as previously defined in (6).

Finally, the skewed Student APARCH model is re-formulated by Lambert and Laurent (2001) with the skewed Student density expressed in terms of the mean and variance and the random error term is specified as $e_{\mathrm{t}}=h_{\mathrm{t}} \varepsilon_{\mathrm{t}}$ and $\varepsilon_{t}$ is iid $\operatorname{SKST}(0,1, \xi, v)$ ie the standardized skewed Student distribution and $\xi$ is the asymmetric coefficient of the Student distribution. The conditional standard deviation of the skewed Student APARCH model is defined in (6). The sign of the distributional asymmetry coefficient or third moment, $\xi$, represents the direct of skewness. If the third moment is positive (negative) then the density is skewed to the right (left). Full specifications of the APARCH models are presented in Giot and Laurent (2003a, 2003b). 


\section{EMPIRICAL RESULTS}

The estimated coefficients, standard errors and $p$-values for the conditional mean and variance equations for the five different GARCH processes are presented in Table 2. All of these models include the impact of news arrival as proxied by the contemporaneous volume of demand, time-ofday, day-of-week and month-of year (calendar) effects as exogenous variables in the conditional variance equation. However, due to the very large number of estimated calendar effects, the tabled conditional variance equations do not include all coefficients, but these are graphically represented. In brief, on the basis of the log-likelihood, Akaike Information (AIC) and Schwartz Criteria (SC), the skewed Student APARCH is the best model for all markets with the exception of the SA market where the Student APARCH model is slightly better. Clearly, either of these two processes have the ability to accommodate the non-normal or fat-tailed characteristics of Australian electricity markets. Only the skewed Student APARCH model is used to provide graphical representations of the calendar effects in Figures 2-4. All results are obtained using G@ARCH 3.0 an Ox package for estimating different ARCH models (Laurent and Peters, 2002).

\section{$<$ TABLE 2 HERE $>$}

To start with, the estimated coefficients, standard errors and $p$-values for the conditional mean return equations $\left(\tau_{0}\right.$ and $\left.\tau_{1}\right)$ for the GARCH model are presented in the uppermost panel of Table 2 . All electricity markets exhibit a significant own mean spillover from their own lagged price relative $\left(\tau_{1}\right)$. In all cases, the mean spillovers are positive ranging from 0.1503 (SA) to 0.1722 (NSW). The uppermost panel of Table 2 also presents the estimated coefficients, standard errors and $p$-values for the conditional variance equation. The own-innovation or ARCH spillovers $\left(\alpha_{1}\right)$ in all four markets are significant indicating the presence of significant ARCH effects, while the lagged volatility or GARCH spillovers $\left(\beta_{1}\right)$ are also significant and larger in magnitude. The respective innovation and volatility spillovers are 0.4319 and 0.5345 in the NSW market, 0.1607 and 0.8803 in the QLD market, 0.0984 and 0.9222 in the SA market and 0.0485 and 0.9473 in the VIC market respectively. The sum of the ARCH and GARCH effects is greater than one in the QLD and SA markets, suggesting that the shocks are permanent, while the values of less than one in the NSW and VIC markets implies a mean reverting conditional volatility process. That is, the shocks are transitory in nature. It should be noted that NSW and VIC are the largest, longest-established and most competitive markets among all Australian electricity markets.

The uppermost panel of Table 2 also includes the estimated coefficients and standard errors for the variable used to proxy the arrival of new information; that is, the contemporaneous volume 
of demand $\left(\psi_{1}\right)$. There is a significant positive relationship between price volatility and contemporaneous volume of demand for all four markets ranging from 0.0616 (VIC) to 0.4063 (NSW). This would suggest that the arrival of new information in the form of the volume of demand has the role of increasing price volatility. The Ljung-Box Q-statistics, $\mathrm{Q}^{2}(10)$, and $p$-values are computed on the squared standardized residuals to test the null hypothesis that there is no remaining heteroskedasticity. The significance of the Ljung-Box Q-statistics in SA and VIC for the GARCH model implies that some residual heteroskedasticity remains in these markets.

The next-to-uppermost panel of Table 2 provides the estimated coefficients, standard errors and p-values for the Risk Metrics model. The magnitude and significance of the estimated Risk Metrics parameters are very similar to that of the GARCH process with the exception that the innovation and volatility spillover effects sum to one. The significance of the Ljung-Box Qstatistics in all markets for the Risk Metrics model once again suggests that this process has not overcome the problem of heteroskedasticity. Of course, it is well known that the Risk Metrics process can model the volatility clustering but not the non-normal characteristics of many time series. The middlemost panel of Table 2 presents the estimated parameters for the normal APARCH model. Once again, all markets exhibit a significant own mean spillover from their own lagged price relative $\left(\tau_{1}\right)$ with the mean spillovers ranging from 0.1664 (QLD) to 0.2596 (VIC). The innovation and volatility spillovers are significant with the volatility spillovers generally larger in magnitude. The respective innovation and volatility spillovers are 0.2730 and 0.4886 for NSW to 0.3081 to 0.6606 for SA. There is also a significant positive relationship between price volatility and contemporaneous volume of demand for all four markets ranging from 0.0835 (QLD) to 0.2156 (NSW).

The asymmetric volatility response $\left(\gamma_{1}\right)$ in the normal APARCH model is negative and significant for all four markets indicating an asymmetric response for positive price relatives in the conditional variance equation and reflects the condition that volatility tends rise in response to 'good news or positive spikes' and fall in response to 'bad news or negative spikes'. This lies counter to the usual expectation in stock markets where downward movements (falling returns) are followed by higher volatility than upward movements (increasing returns). The power coefficients $(\delta)$ of the standard deviation process are significant for all markets ranging from 1.0365 (QLD) to 1.2752 (SA). These coefficients are significantly different from two and one indicating it is more relevant to model the conditional standard deviation of electricity markets in a non-linear form. However, the Ljung-Box Q-statistics calculated on the squared standardized residuals are still 
significant for the NSW, SA and VIC markets indicating that this model has still not eliminated the problem of heteroskedasticity.

The next-to-lowermost panel of Table presents the estimated parameters for the Student APARCH model. Here, the mean spillovers are significant for all four markets, range from 0.1462 (QLD) to 0.3092 (VIC). The innovation and volatility spillovers are also significant across the four markets with the volatility spillovers greater in magnitude than the innovation spillovers. There is a significant positive relationship between the contemporaneous volume of demand and volatility for all markets. Once again, and in contrast to many stock markets, the asymmetric volatility response $\left(\gamma_{1}\right)$ is negative and significant for all markets indicating an asymmetric response for positive price relatives in the conditional variance equation, i.e. volatility rises in response to 'good news or positive spikes' and falls in response to 'bad news or negative spikes'. The power coefficients $(\delta)$ of the standard deviation process are also significant for all markets ranging from 1.0191 (VIC) to 1.6070 (NSW). As before, a non-linear conditional standard deviation equation is required. The tail coefficients (v)are also significant and together with the insignificance of the Ljung-Box Qstatistics for the squared standardized residuals in all markets indicate that the Student distribution has taken account of the fat tailed and heteroskedasticity characteristics of the electricity price relative series.

Finally, the lowermost panel of Table 2 presents the estimated coefficients, standard errors and p-values for the skewed Student model. All markets are shown to exhibit a significant own mean spillover from their own lagged price relative $\left(\tau_{1}\right)$. In all cases, the mean spillovers are positive ranging from 0.1811 (SA) to 0.2462 (VIC). Put differently, according to the skewed Student APARCH model, a ten percent increase in the VIC electricity price in the current period Granger causes an increase of 2.462 percent over the next half-hour. Likewise, a ten percent increase in prices for SA will Granger cause a 1.811 percent increase over the next half-hour. The own-innovation $\left(\alpha_{1}\right)$ in all four markets is also significant indicating the presence of significant ARCH effects. The lagged volatility or GARCH spillovers $\left(\beta_{1}\right)$ are also significant. For the skewed Student APARCH specification, the ARCH effects are larger in magnitude than the GARCH effects in the NSW (0.4376 and 0.3677) and VIC (0.5761 and 0.3057) markets while the reverse is true for QLD (0.3858 and 0.4337) and SA (0.2530 and 0.5422). This implies that for NSW and VIC the last period's volatility shocks in electricity price relatives have a lesser effect on its future volatility than the memory of previous surprises or innovations. This is comparable to the only known study (though using daily data) by Solibakke (2002) which discovered “...high past shock effects $(\mathrm{ARCH})$ and rather low past volatility effects (GARCH)”. 
The estimated coefficients for $\psi_{1}$ indicates a significant positive relationship between price volatility and the contemporaneous volume of demand for all four markets ranging from 0.0621 (VIC) and 0.2605 (SA). This would suggest that the role of new information in the form of demand load has a greater role of increasing price volatility in the SA market than any other market. The estimated asymmetric volatility response coefficients to market news $\left(\gamma_{1}\right)$ in the skewed Student model are significant and negative for all markets. This lies counter to the results of the Student APARCH model. But by way of comparison, Solibakke (2002: 28) found “...insignificant asymmetric volatility coefficient for all specifications in the (Nordic) spot market suggesting equal reaction patterns to positive and negative shocks" while Hadsell, Marathe and Shawky (2004) estimated that the asymmetric effect was also significant and negative thus capturing a strong market response to 'negative' news in US electricity markets when employing a Threshold ARCH model.

The power coefficient $(\delta)$ of the standard deviation process for VIC is significantly different from one, while the power coefficients for NSW, SA and QLD are all significantly different from two and one, thus indicating it is more appropriate to model a non-linear conditional standard deviation equation. The asymmetric coefficients $(\xi)$ are positive and significant for the markets and range from 0.0703 (NSW) to 0.1036 (SA). The positive asymmetry coefficients represent the price relative series are skewed to the right. The tail coefficients $(v)$ in the skewed Student APARCH specification are also significant for the four markets representing that the skewed Student distribution has again taken account of the fat right-skewed characteristic of all series. The insignificance of the Ljung-Box Q-statistics on the squared standardized residuals for the four markets would indicate that the skewed Student distribution (like the Student APARCH) has overcome the problem of heteroskedasticity in the series.

Figures 2 to 4 depict the volatility effects of the arrival of new information for the time-of day $\left(\varphi_{\mathrm{i}}\right)$, day-of-week $\left(\eta_{\mathrm{i}}\right)$ and month-of-year $\left(\zeta_{\mathrm{i}}\right)$ effects in the skewed Student APARCH model. Tests in Table 3 of the null hypotheses that all time-of-day coefficients (not shown) are jointly zero reject the null hypotheses at the 0.10 level or lower in three markets with the exception of the NSW market, indicating that the time-of-day has a systematic influence on electricity price volatility in Australia. Some interesting patterns are illustrated in Figure 2, with price volatility increasing from midnight and reaching a maximum between 5:30 and 7:30, falling and increasing again until another maximum is reached between 17.00 and 18:30 and then falling again and peaking again between 21:30 to 23:00. The day-of-week effects are depicted in Figure 3. Hypothesis tests of joint insignificance are likewise rejected with the exception of the SA market. Volatility in the QLD and 
SA markets is shown to be highest on Monday, falling progressively through the week. In the NSW market, however, volatility increases during the week and falls over the weekend. Volatility is lowest on Wednesday in SA, on Friday in QLD and VIC and on Saturday in NSW.

\section{$<$ TABLE 3 HERE $>$}

The month-of-year volatility effects as estimated by the skewed Student APARCH process are presented in Figure 4. Joint tests for month-of-year effects in Table 3 are once again significant for all four markets. A familiar price volatility pattern emerges with volatility being highest in June, July and August (winter) and December and January (summer). By way of comparison, Solibakke's (2002) analysis of the Nordic spot electricity market also indicated that peaks in price volatility corresponded with peak demand, though just in summer. However, Hadsell, Marathe and Shawky (2004) found that while calendar months exhibited different volatility behavior in US electricity markets, none was unique with respect to magnitude or volatility. The month-of-year effects are also jointly significant in explaining price relative volatility in the four markets.

\section{$<$ FIGURES 2-4 HERE $>$}

In summary, and according to all five models, all four markets exhibit a significant own mean spillover from their own lagged price relative $\left(\tau_{1}\right)$. In all cases, the mean spillovers are positive. The own-innovation or ARCH spillovers $\left(\alpha_{1}\right)$ are also all significant indicating the presence of strong $\mathrm{ARCH}$ effects, while the lagged volatility or GARCH spillovers $\left(\beta_{1}\right)$ are also significant and larger in magnitude for the first four models. In the skewed Student APARCH models for QLD and SA the GARCH effects are also larger, but the reverse is true for NSW and VIC. The estimated coefficients for news arrival denoted by the contemporaneous volume of demand are all positive and significant thus implying that increases in demand increase price volatility. In addition, the three APARCH models indicate that the estimated asymmetric coefficients $\left(\gamma_{1}\right)$ are significant and negative for all four regional markets indicating that positive shocks (good news) are associated with higher volatility than negative shocks (bad news). This lies counter to evidence from stock markets. In most cases, the power coefficients $(\delta)$ of the standard deviation processes are all positive and significantly different from one and two, thus indicating it is more relevant to model the conditional standard deviation in a non-linear form. Finally, the asymmetric coefficients of the Student distribution $(\xi)$ are positive and significant for the four markets indicating the price relative series are skewed to the right. 


\section{CONCLUDING REMARKS}

This study presents an analysis of intraday electricity price volatility in the four Australian electricity markets of New South Wales, Queensland, South Australia and Victoria. The data consists of half-hourly prices for the period 1 January 2002 to 1 June. Five different GARCH volatility processes consisting of the GARCH, Risk Metrics, normal, Student and skewed Student APARCH models are estimated. The results indicate that intraday price volatility in most of the Australian electricity markets is best described by an asymmetric skewed Student APARCH specification. This accommodates both the right-skewed, fat-tailed properties of the observed data and the contemporaneous volume of demand, time-of-day, day-of-week and month-of-year effects as proxies for the arrival of new market information. In sum, an increase in the volume of demand, positive price spikes, early-morning, late afternoon and early evening hours, Mondays and peak winter and summer months are all associated with significantly higher volatility than low demand volumes, negative price spikes and other times of the day, week and year. This suggests that systematic influences on electricity price volatility can be easily quantified from readily available market information.

However, the market, information and calendar effects examined are at best only a partial explanation for the price volatility found in Australian electricity markets. Fortunately, other influences have been put forward and these provide fruitful avenues for further research, especially building upon the range of GARCH models used in this study. One distinct possibility is market power. Robinson and Baniak (2002), for example, have argued that generators with market power might have the incentive to create volatility in the spot market in order to benefit from higher risk premiums in the contract market. Proxying changes in the competitive environment may then be able to provide empirical evidence whether competition increases or decreases price volatility. Another potential factor affecting volatility is regulatory change. For example, Robinson and Taylor (1998a, 1998b) have linked changes in regulation and regulatory risk with regional electricity company shares in the United Kingdom and it is feasible that changes in regulatory regimes could be included as exogenous factors in a study of electricity prices more directly.

Similarly, changes in purchasing or contracting behavior by large purchasers of electricity may also have an influence on price volatility. Smith (2003), for instance, argues that the US spot electricity markets lost much of their volatility as large consumers, like California, moved out of electricity purchases to long-term contracts. Finally, there is the prospect to examine volatility interactions between geographically close and linked markets using variants of the GARCH models used in the current analysis. For example, Herbert (2002) discusses the interactions between the 
electricity and gas markets as substitutable sources of energy. Worthington, Kay-Spratley, and Higgs (2003) examine the volatility interactions between regional electricity markets, though using only basic GARCH models with no allowance for systematic influences on electricity price volatility.

\section{REFERENCES}

Alexander, C. (2001) Market Models (Wiley)

Andersen, T. and T. Bollerslev (1997) "Intra-day periodicity and volatility persistence in financial markets." Journal of Empirical Finance 4(1): 115-158.

Andersen, T. and T. Bollerslev (1998) "Deutsche mark-dollar volatility: Intraday activity patterns macroeconomic announcements, and long run dependencies." Journal of Finance 53(1): 219-265.

Andersen, T.G. (1996). "Return volatility and trading volume: An information flow interpretation of stochastic volatility." Journal of Finance 51(1): 169-204.

Bauwens, L. and P. Giot (2001) Econometric modeling of stock market intraday activity (Kluwer)

Bera, A.K. and M.L. Higgins (1993) "ARCH models: properties, estimation and testing." Journal of Economic Surveys 7(4): 305-366.

Blankinship, S. (2003) “Distributed generation: It's all a matter of control.” Power Engineering 107(8): 22-26.

Bollerslev, T. (1986) "Generalised autoregressive condition heteroskedasticity." Journal of Econometrics 31(3): 307327.

Bollerslev, T., R.Y. Chou and K.F. Kroner (1992) "ARCH modeling in finance: a review of the theory and empirical evidence.” Journal of Econometrics 52(1): 5-59.

De Vany, A.S. and W.D. Walls (1999a) "Co integration analysis of spot electricity prices: insights on transmission efficiency in the western US." Energy Economics 21(3): 435-448.

De Vany, A.S. and W.D. Walls (1999b) "Price dynamics in a network of decentralized power markets." Journal of Regulatory Economics 15(2): 123-140.

Dickson, A. and S. Warr (2000) "Profile of the Australian Electricity Industry." Australian Bureau of Agricultural and Resource Economics (ABARE) Research Report No. 2000.7, Canberra.

Ding, Z., C.W.J. Granger and R.F. Engle (1993). "A long memory property of stock market returns and a new model." Journal of Empirical Finance 1(1): 83-106.

Engle, R.F. (1982). "Autoregressive conditional heteroskedasticity with estimates of the variance of UK inflation." Econometrica 50(4): 987-1008.

Engle, R.F. and V.K. Ng (1993). "Measuring and testing the impact of news on volatility." Journal of Finance 48(5): 1749-1778.

Escribano, A., J.I. Pena and P. Villaplana (2002). “Modeling electricity prices: International evidence.” Working paper 02-27, Economics Series 08, Departqmento de Economia, Universidad Carlos III de Madrid.

Foster, A. (1995). "Volume volatility relationships for crude oil futures markets." Journal of Futures Markets 15(8): 929-951.

Giot, P. and S. Laurent (2003a). “Market risk in commodity markets: A VaR approach.” Energy Economics 25(5): 435457.

Giot, P. and S. Laurent (2003b). "Value-at-risk for long and short trading positions." Journal of Applied Econometrics 18(6): 641-664.

Hadsell, L., A. Marathe and H.A. Shawky (2004). "Estimating the volatility of wholesale electricity spot prices in the US." The Energy Journal 25(4): 23-40.

Herbert, J. (2002). "Power prices today: Growing more unpredictable.” Public Utilities Fortnightly 140(18): 28-35.

International Energy Agency (2001). Energy Policies of IEA Countries: Australia 2001 Review, Organization for Economic Cooperation and Development (OECD), Paris.

Lambert, P. and S. Laurent (2001). "Modeling financial time series using GARCH-type models and a skewed Student density." Mimeo, University de Liege.

Lamoureux, C. and W. Lastrapes (1990). "Heteroskedasticity in stock return data: Volume verses GARCH effects." Journal of Finance 45(1): 221-229.

Laurent, S. (2004). "Analytical derivates of the APARCH model." Computational Economics 24(1): 51-57.

Laurent, S. and J.P. Peters (2002). "G@ARCH 2.2: An Ox package for estimating and forecasting various ARCH models." Journal of Economic Surveys 16(3): 447-485.

Lucia, J.J. and E.S. Schwartz (2001). "Electricity Prices and Power Derivatives: Evidence for the Nordic Power Exchange." University of California Los Angeles Working Paper, Los Angeles. 
National Electricity Market Management Company Limited (2001). An Introduction to Australia's National Electricity Market, NEMMCO, Melbourne.

National Electricity Market Management Company Limited (2003). WWW site: <http://www.nemmco.com.au/>. Accessed August 2003.

Newbery, D.M. (1995). "Power markets and market power.” Energy Journal 16(3): 39-66.

Pagan, A. (1996). "The econometrics of financial markets." Journal of Empirical Finance 3(1): 15-102.

Rahman, S., C.F. Lee and K.P. Ang (2002). "Intraday return volatility process: Evidence from NASDAQ stocks." Review of Quantitative Finance and Accounting 19(1): 155-180.

Robinson, T. (2000). "Electricity pool series: a case study in non-linear time series modeling." Applied Economics 32(5): 527-532.

Robinson, T. and A. Baniak (2002). "The volatility of prices in the English and Welsh electricity pool." Applied Economics 34(12): 1487-1495.

Robinson, T.A. and M.P. Taylor (1998a). "Regulatory uncertainty and the volatility of regional electricity company share prices: The economic consequence of Professor Littlechild." Bulletin of Economic Research 50(1): 37-44.

Robinson, T.A. and M.P. Taylor (1998b). "The effects of regulation and regulatory risk in the UK electricity distribution industry." Annals of Public and Cooperative Economics 69(3): 331-346.

Schwert, W. (1990). "Stock volatility and the crash of '87." Review of Financial Studies 3(1): 77-102.

Smith, R. (2003). "Leading the news: Surplus of electricity may persist at least until 2005." Wall Street Journal 12 February, A3.

Solibakke, P. (2002). "Efficient estimated mean and volatility characteristics for the Nordic spot electricity power market." International Journal of Business 7(2): 17-35.

Taylor, S. (1986) Modeling Financial Time Series (Wiley).

Walls, W.D. (1999). "Volatility, volume and maturity in electricity futures." Applied Financial Economics 9(3): 283287.

Wang, G. and J. Yau (2000). "Trading volume, bid-ask spread, and price volatility in future markets." Journal of Futures Markets 20(10): 943-970.

Wolak, F.A. (2000). "Market Design and price behavior in restructured electricity markets: An international comparison". NBER-East Asia Seminar on Economics, vol. 8. Chicago and London: University of Chicago Press.

Worthington, A.C., A. Kay-Spratley and H. Higgs (2003). "Transmission of prices and price volatility in Australian electricity spot markets: A multivariate GARCH analysis.” Energy Economics (forthcoming). 
Table 1 Descriptive Statistics for Australian Electricity Price Relatives by Market

\begin{tabular}{|lrrrr|}
\hline & NSW & \multicolumn{1}{c}{ QLD } & \multicolumn{1}{c}{ SA } & \multicolumn{1}{c|}{ VIC } \\
\hline Observations & 24767 & 24767 & 24767 & 24767 \\
Mean & $-8.69 \mathrm{E}-04$ & $-1.08 \mathrm{E}-03$ & $-8.98 \mathrm{E}-04$ & $-8.03 \mathrm{E}-04$ \\
Median & -0.5786 & -0.6237 & -0.1833 & -0.7168 \\
Maximum & 394.2530 & 489.1307 & 472.6716 & 477.6408 \\
Minimum & -494.5365 & -476.5178 & -483.8354 & -479.5675 \\
Standard deviation & 22.4033 & 29.4379 & 24.3649 & 22.5804 \\
Skewness & 0.5556 & 0.6545 & 0.2788 & 1.0585 \\
Kurtosis & 84.3674 & 80.5308 & 76.4694 & 77.9228 \\
Jarque-Bera statistic & $6.83 \mathrm{E}+06$ & $6.20 \mathrm{E}+06$ & $5.57 \mathrm{E}+06$ & $5.80 \mathrm{E}+06$ \\
JB $p$-value & 0.0000 & 0.0000 & 0.0000 & 0.0000 \\
\hline
\end{tabular}

This table provides measures of central tendency, dispersion and shape for the changes in the half-hourly spot prices for NSW - New South Wales, QLD - Queensland, SA - South Australia and VIC - Victoria. The sample period is from 1January 2002 to 1 June 2003. The critical values of significance for skewness and kurtosis at the .05 level are 0.0305 and 0.0610 , respectively. JB - Jarque-Bera.

Figure 1 Australian Electricity Price Relatives by Market
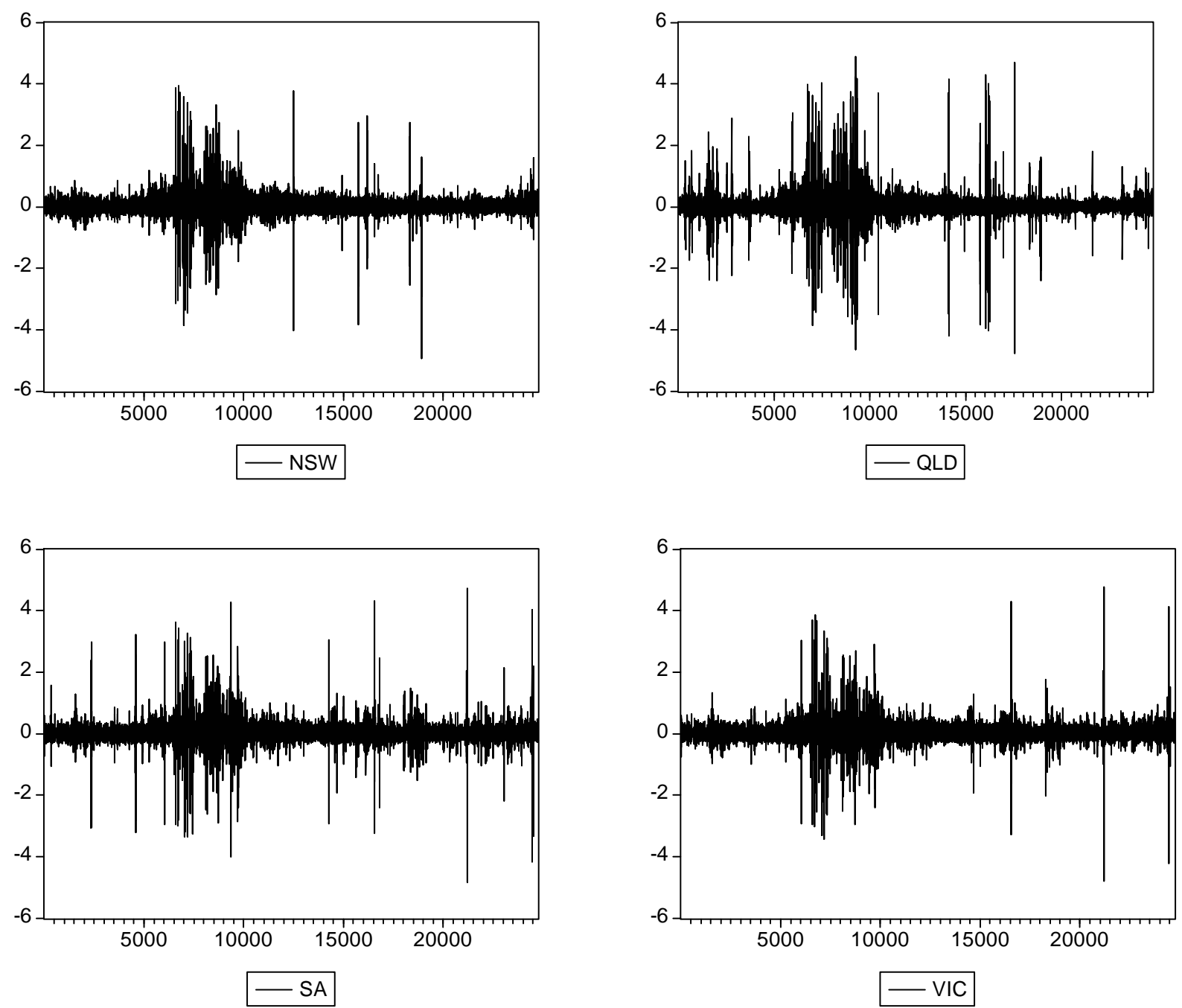
Table 2 Estimated Coefficients for Conditional Mean Price and Variance Covariance Equations

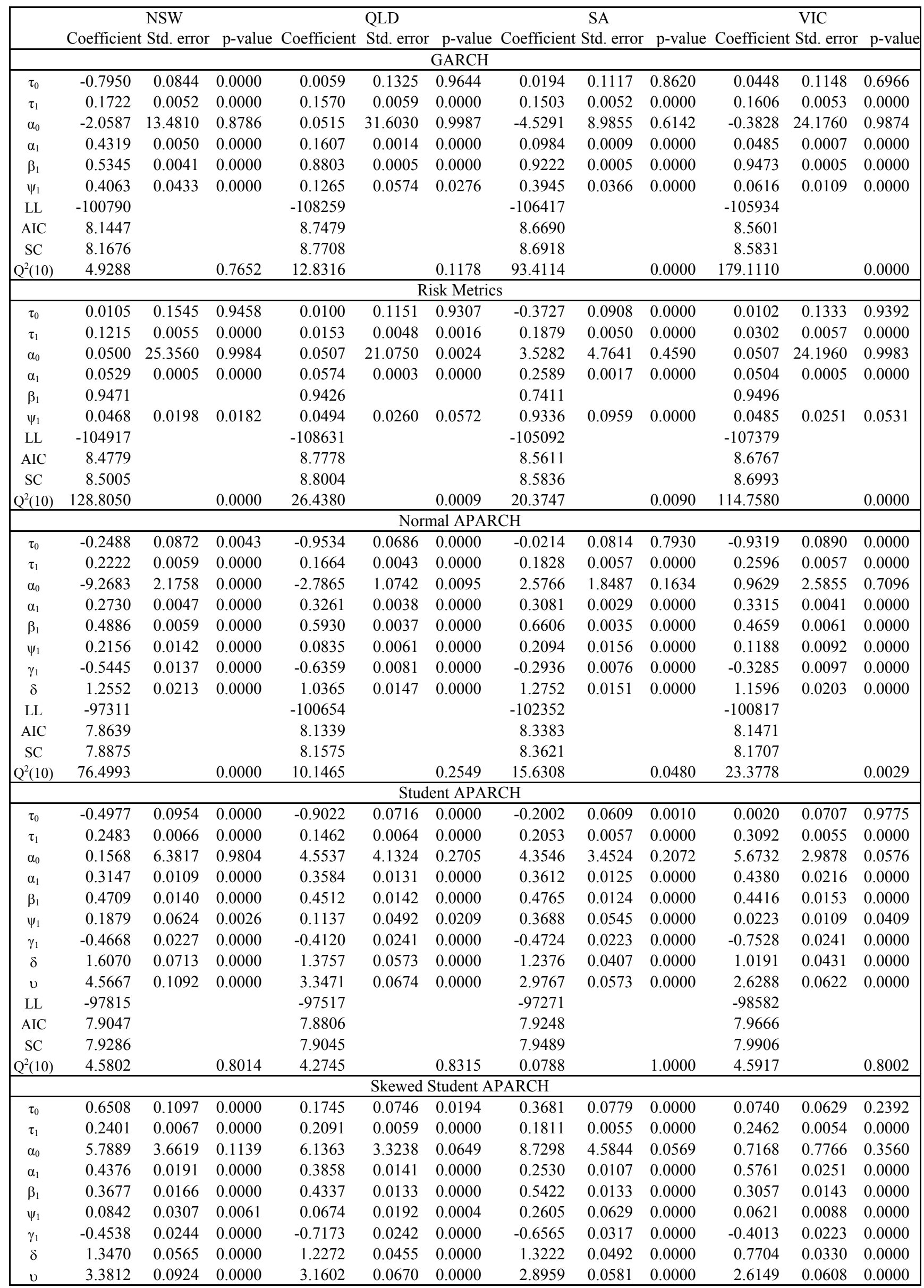




\begin{tabular}{|c|c|c|c|c|c|c|c|c|c|c|c|c|}
\hline & \multicolumn{3}{|c|}{ NSW } & \multicolumn{3}{|c|}{ QLD } & \multicolumn{3}{|c|}{ SA } & \multicolumn{3}{|c|}{ VIC } \\
\hline & Coefficient & Std. error & p-value & Coefficient & Std. error & p-value & Coefficient & Std. error & p-value & Coefficient & Std. error & p-value \\
\hline$\xi$ & 0.0703 & 0.0102 & 0.0000 & 0.0891 & 0.0087 & 0.0000 & 0.1036 & 0.0081 & 0.0000 & 0.0877 & 0.0074 & 0.0000 \\
\hline LL & -96662 & & & -96542 & & & -97645 & & & -98064 & & \\
\hline AIC & 7.8117 & & & 7.8020 & & & 7.9553 & & & 7.9249 & & \\
\hline $\mathrm{SC}$ & 7.8359 & & & 7.8262 & & & 7.9797 & & & 7.9491 & & \\
\hline$Q^{2}(10)$ & 11.8230 & & 0.1593 & 2.0073 & & 0.9808 & 1.6953 & & 0.9890 & 0.0790 & & 1.0000 \\
\hline
\end{tabular}

This table provides the estimated coefficients, standard errors and $p$-values for the mean and conditional standard deviation equations for the NSW - New South Wales, QLD - Queensland, SA - South Australia and VIC - Victoria electricity markets. $\tau_{0}$ is the constant in the conditional mean equation, $\tau_{1}$ is the degree of mean spillover, $\alpha_{0}$ is the constant in the conditional standard deviation equation, $\alpha_{1}$ is the ARCH coefficient, $\beta_{1}$ is the GARCH coefficient, $\gamma_{1}$ is the leverage effect, $\psi_{1}$ is the coefficient to the contemporaneous volume of demand, $\delta$ is the power of the conditional standard deviation process, $v$ is the degrees of freedom, $\xi$ is the asymmetric coefficient. LL is the log likelihood, AIC and SIC are the Akaike Information Criterion and Schwartz Criteria, respectively. $Q^{2}(10)$ is the Ljung-Box $Q-$ statistic on the squared standardized residuals of order 10.

Table 3 Joint hypothesis tests for estimated variance covariance coefficients

\begin{tabular}{|lrrrrrrrrr|}
\hline & & \multicolumn{2}{c}{ NSW } & \multicolumn{2}{c}{ QLD } & \multicolumn{2}{c|}{ SA } & \multicolumn{2}{c|}{ VIC } \\
\hline & df & $\chi^{2}$ & p-value & $\chi^{2}$ & p-value & $\chi^{2}$ & p-value & $\chi^{2}$ & p-value \\
Time-of-day & 47 & 29.8545 & 0.9758 & 62.0277 & 0.0698 & 61.6563 & 0.0742 & 65.6096 & 0.0376 \\
Day-of-week & 6 & 27.9899 & 0.0001 & 33.8892 & 0.0000 & 9.7213 & 0.1369 & 39.4242 & 0.0000 \\
Month-of-year & 11 & 29.3993 & 0.0020 & 41.4733 & 0.0000 & 35.9321 & 0.0002 & 53.5040 & 0.0000 \\
\hline
\end{tabular}

This table presents joint hypothesis tests for the estimated conditional standard deviation coefficients in Table 2 for NSW - New South Wales, QLD - Queensland, SA - South Australia and VIC - Victoria. The joint significance tests are $\chi^{2}$ tests that all coefficients are jointly zero for the skewed Student APARCH model, demand volume, time-ofday, day-of-week and month-of-year coefficients.

Figure 2 Time-of day effects for the skewed Student APARCH model by market

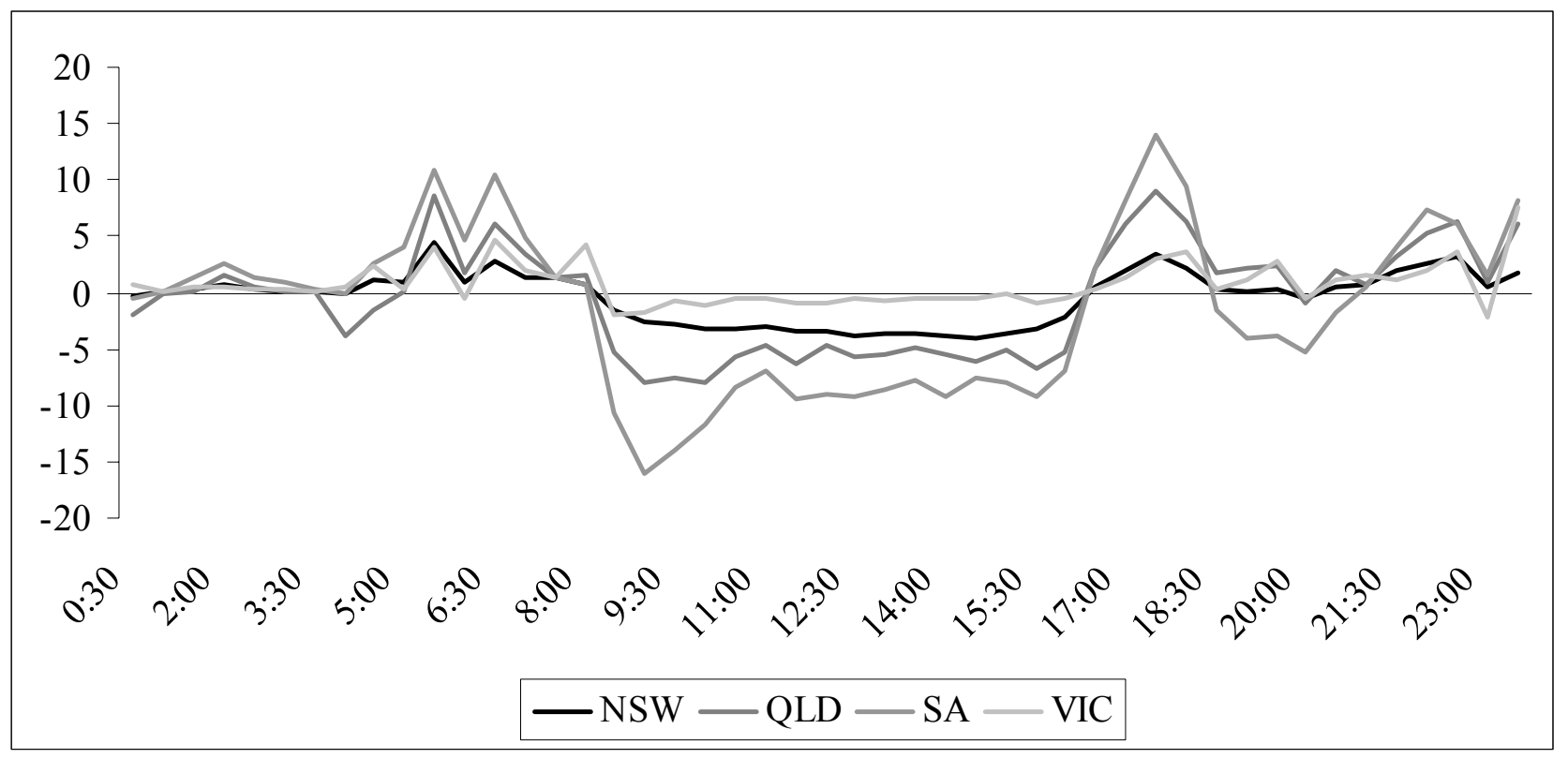


Figure 3 Day-of-week effects for the skewed Student APARCH model by market

Figure 4 Month-of-year effects for the skewed Student APARCH model by market

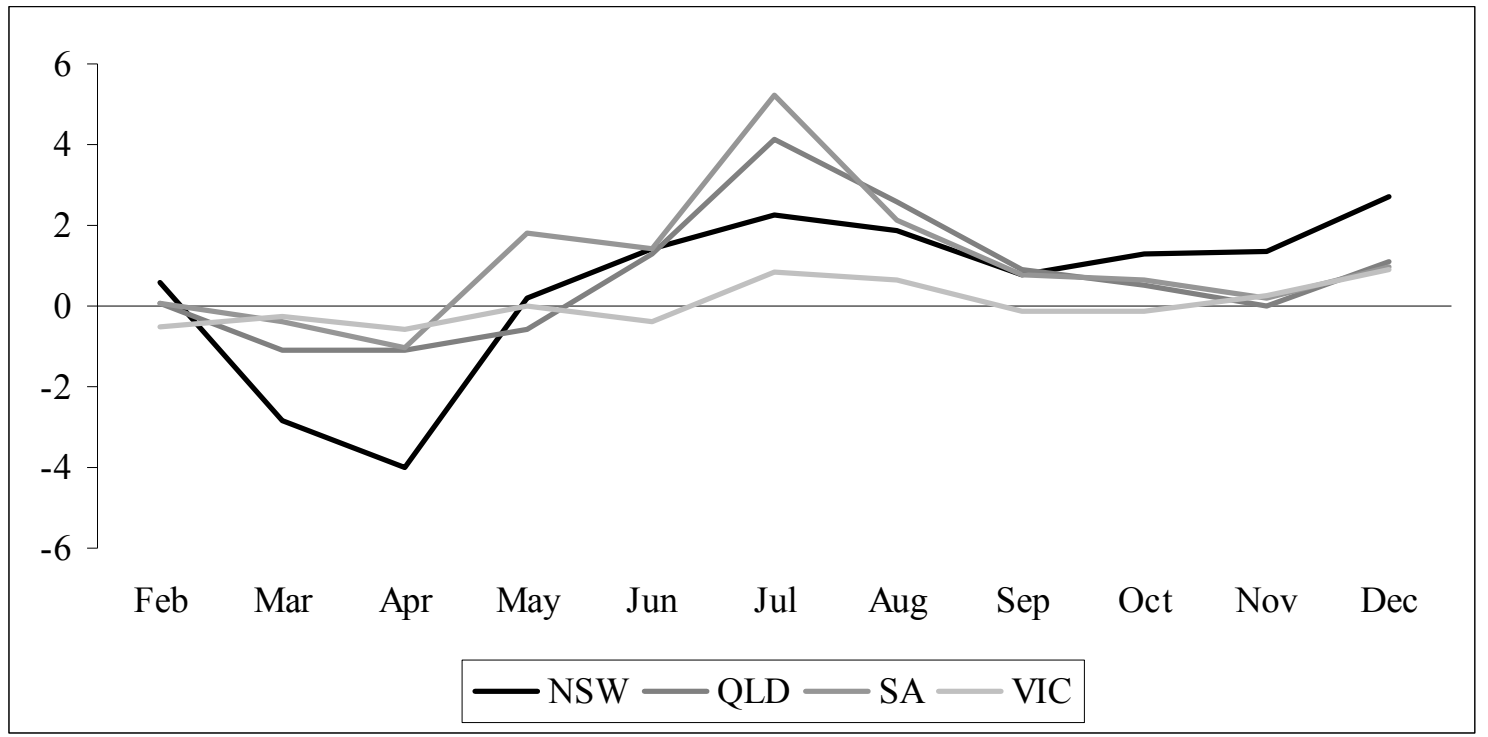




\section{LISTING OF DISCUSSION PAPERS - 2003}

Lahiri R, A Further Exploration of Some Computational Issues in

Equilibrium Business Cycle Theory, No 136, February 2003

Valadkhani A, How Many Jobs Were Lost With the Collapse of Ansett? No 137, February 2003

Drew M E, Naughton T, \& Veerarghavan M, Is Idiosyncratic Volatility Priced? Evidence from the Shanghai Stock Exchange, No 138, February 2003

Valadkhani, A, Does the Term Structure Predict Australia's Future Output Growth? No 139, February 2003

Worthington A, \& Higgs $\mathrm{H}, \mathrm{A}$ Multivariate GARCH Analysis of the Domestic Transmission of Energy Commodity Prices and Volatility: A Comparison of the Peak and Off-peak Periods in the Australian Electricity Spot Market, No 140, February 2003

Li S, The Estimation of Implied Volatility from the Black-Scholes Model: Some New Formulas and Their Applications, No 141, February 2003

Drew M E, \& Stanford, J D, Principal and Agent Problems in Superannuation Funds, No 142, March 2003

Li S, A Single-Period Model and Some Empirical Evidences for Optimal Asset Allocation with Value-at-Risk Constraints, No 143, March 2003

Valadkhani A, An Empirical Analysis of the Black Market Exchange Rate in Iran, No 144, April 2003

Worthington A, Business Expectations and Preferences regarding the Introduction of Daylight Saving in Queensland, No 145, May 2003

Worthington A, Losing Sleep at the Market: An Empirical Note on the Daylight Saving Anomaly in Australia, No 146, May 2003
Robinson M, Tightening the Results/Funding Link in Performance Budgeting Systems, No 147, May 2003

Worthington A, \& Higgs H, Risk, Return and Portfolio Diversification in Major Painting Marketing: The Application of Conventional Financial Analysis to Unconventional Investments, No 148, June 2003

Valadkhani A, Demand for M2 in Developing Countries: An Empirical Panel Investigation, No 149, July 2003

Worthington $A$, \& Higgs $H$, Modelling the Intraday Return Volatility Process in the Australia Equity Market: An Examination of the Role of Information Arrival in S \& PASX Stocks, No 150, July 2003

Lahiri R, Tax Distortions in a Neoclassical Monetary Economy in the Presence of Administration Costs, No 151 September 2003

Layton A, \& Smith D, Duration Dependence in the US Business Cycle, No 152, August 2003

Valadkhani A, \& Layton A, Quantifying the Effect of GST on Inflation in Australia's Capital Cities: An Intervention Analysis, No 153, September 2003

Worthington A, \& Valadkhani A, Measuring the Impact of Natura Disasters on Capital Markets: An Empirical Application Using Intervention Analysis, No 154, September 2003

Robinson M, The Output Concept and Public Sector Services, No 155 September 2003

Worthington A, Brown K, Crawford M, \& Pickernell D, Socio-Economic and Demographic Determinants of Household Gambling in Australia, No 156, September 2003 
Worthington A, \& Higgs $\mathrm{H}$, Tests of Random Walks and Market Efficiency in Latin American Stock Markets: An Empirical Note, No 157, September 2003

(Replacing Previous No 158) Worthington A, \& Higgs H, Systematic Features of High-Frequency Volatility in Australian Electricity Markets: Intraday Patterns, Information Arrival and Calendar Effects, No 158,

November 2003

Worthington A, \& Higgs $\mathrm{H}$, Weak-form Market Efficiency in European Emerging and Developed Stock Markets, No 159, September 2003

West T, \& Worthington A, Macroeconomic Risk Factors in Australian Commercial Real Estate, Listed Property Trust and Property Sector Stock Returns: A Comparative Analysis using GARCH-M, No 160 October 2003

Lee B, Interstate Comparison of Output and Productivity in the Australian Agricultural Sector - 1991 - 1999, No 161, October 2003

McCarthy S, Hedging Versus not Hedging: Strategies for Managing Foreign Exchange Transaction Exposure, No 162, November 2003

Worthington A, Emergency Finance in Australian Households: An Empirical Analysis of Capacity and Sources, No 163, November 2003

Worthington C, Debt as a Source of Financial Stress in Australian Households, No 164, November 2003

Robinson M, The Australian Budgeting System: On the Cusp of Change, No 165, November 2003

Lahiri R, Cooperation v/s Non-cooperation in R\&D Competition with Spillovers, No 166, December 2003
Wolff R, Yao Q, \& Tong H, Statistical Tests for Lyapunov Exponents of Deterministic Systems, No 167, December 2003

Wolff R, Barnett A, A Time Domain Test for Some Types of NonLinearity, No 168 December 2003

\section{LISTING OF DISCUSSION PAPERS - 2004}

Drew M, Veeraraghavan M, Ye M, Do Momentum Strategies Work? Australian Evidence, No 169, January 2004

Drew M, Mallin M, Naughton T, Veeraraghavan M, Equity Premium: Does it Exist? - Evidence from Germany and United Kingdom, No 170, January 2004

Layton A, Valadkhani A, Measures of National Export Price Volatility Based on the Capital Asset Pricing Model, No 171, January 2004

Drew M, Marsden A, Veeraraghavan M, Small Firm Effect, Liquidity and Security Returns: Australian Evidence, No 172, February 2004

Drew M, Stanford J, Portability of Superannuation Balances, No 173 March 2004

Drew M, Naughton T, Veeraraghavan M Pricing of Equities in China: Evidence from the Shanghai Stock Exchange No 174, May 2004

Valadkhani A, Worthington A, Layton A, An Analysis of the Rising Cost of Education in Australia, No 175, April 2004

Li S, Worthington A, The Relationship Between The Adoption of Internet Banking and Electronic Connectivity: - An International Comparison, No 176, May 2004

Drew M, Marsden A, Veeraraghavan M, Does Idiosyncratic Volatility Matter? - New Zealand Evidence, No 177, May 2004 
Guégan D, How Can We Dane the Concept of Long Memory? - An

Econometric Survey, No 178, April 2004

Clements A, Hurn S, White S, Discretised Non-Linear Filtering for

Dynamic Latent Variable Models: with Application to Stochastic Volatility

No 179 , May 2004

McCarthy S, Ispriani A, An Operating/Economic Exposure Australian

Case Study: Foster's Group Limited, No 180, May 2004

Lahiri R, On Skill Heterogeneity and Inflation, No 181, June 2004

Bianchi R, Drew M, Polichronis J, A Test of Momentum Trading

Strategies in Foreign Exchange Markets: Evidence from the G7, No 182,

June 2004

Jeisman S, Exchange Market Pressure in Australia, No 183, June 2004

Higgs $\mathrm{H}$, Worthington A, Financial Returns and Price Determinants in

the Australian Art Market - 1973-2003, No 184, July 2004

Worthington, A, The distribution of Financial Literacy in Australia, No

185, November 2004 


\section{QUT}

Queensland University of Technology

DISCUSSION PAPERS IN ECONOMICS, FINANCE AND INTERNATIONAL COMPETITIVENESS

\section{Systematic Features of High-Frequency}

Volatility in Australian Electricity Markets:

Intraday Patterns, Information Arrival and

\section{Calendar Effects}

Helen Higgs

and

All correspondence to:

Associate Professor Andrew C Worthington

Editor, Discussion Papers in Economic, Finance and

International Competitiveness

School of Economics and Finance

Queensland University of Technology

GPO Box 2434, BRISBANE QLD 4001, Australia

\section{Andrew C Worthington}

Discussion Paper No 186, December 2004

Series edited by

Associate Professor Andrew C Worthington

School of Economics and Finance 